\title{
Articles
}

\section{Hitting the Bull's Eye: Attachment Representations and the Organization of Social Networks}

\author{
Elaine Scharfe ${ }^{*}$
}

[a] Department of Psychology, Trent University, Peterborough, Canada.

\begin{abstract}
Hazan and Zeifman were the first to explore Bowlby's proposition that adults would organize their attachment relationships into a hierarchy and since then considerable research has explored both the structure and function of attachment hierarchies using different methodologies. In this study, previous findings establishing an association between attachment and networks were replicated and the associations between network members were explored. First, consistent with expectations, the findings provided additional evidence that romantic partners do not necessarily jump to the top of the hierarchy and young adults continue to place parents, in particular mothers, at the top of their hierarchy. Consistent with previous work, security was associated with placing others closer to the self and attachment avoidance was associated with placing others farther from the self on an electronic bull's eye. Furthermore, to date, this is the first study to examine the association between attachment representations and the organization of network members. Interestingly, security was associated with placing network members closer to each other and attachment avoidance was associated with placing network members farther from each other. This finding suggests that individuals with high attachment security may be more motivated to allow members of their social networks to mingle whereas individuals with high attachment avoidance scores seemed to be motivated to keep their network members at a distance. The results of this study extend our understanding how attachment representations may influence the organization of our social networks.
\end{abstract}

Keywords: attachment, social networks, bull's eye mapping technique

Interpersona, 2020, Vol. 14(1), 15-27, https://doi.org/10.5964/ijpr.v14i1.3919

Received: 2019-05-20. Accepted: 2020-04-24. Published (VoR): 2020-07-02.

*Corresponding author at: Department of Psychology, Trent University, Peterborough, Ontario, Canada K9L 0G2. E-mail: escharfe@trentu.ca

This is an open access article distributed under the terms of the Creative Commons Attribution 4.0 International License, CC BY 4.0

(https://creativecommons.org/licenses/by/4.0/), which permits unrestricted use, distribution, and reproduction in any medium, provided the original work is properly cited.

Bowlby (1969/1997) proposed that although most individuals' first attachment relationship is with their primary parental caregiver, typical development includes the expansion of the attachment network to include other family members and peers. Furthermore, the redistribution of attachment functions, primarily secure base, proximity seeking, and safe haven, adjust with age and changes in relationship status. Hazan and Zeifman (1994) were the first to explore characteristics of attachment networks and, to date, several researchers have explored the structure and function of attachment networks using different methodologies. In particular, attachment researchers have developed measures such as the Attachment Networks Questionnaire (ANQ) to assess the different attachment functions (i.e., secure base, safe haven, proximity seeking, and separation protest) served by members of one's social network. These assessments allow researchers to rank network members in a hierarchy based on their importance in fulfilling attachment needs for individuals. Much of this work has also used the bull's eye technique (Antonucci, 1986) to assess closeness of network members. For example, there is some evidence that attachment security, as compared to attachment insecurity, is associated with reporting 
that social network members are closer (e.g., Julal, Carnelley, \& Rowe, 2017; Pitman \& Scharfe, 2010; Rowe \& Carnelley, 2005). Research using paper and pencil versions of the bull's eye, however, has been limited in the examination of the placement of others with respect to the "center" (you) due to the time consuming reality of needing to measure distance by hand. In this study, an electronic "bull's eye" was used to more easily explore how attachment may influence the organization of members in social networks. Specifically, the electronic bull's eye was programmed to provide the $X$ and $Y$ coordinates as data points and using trigonometry equations it was relatively quick and easy to calculate distances between network members. This study is one of the first studies to provide data highlighting the effects of adult attachment on the organization of social networks.

Over the past 20 years, researchers have confirmed Bowlby's assertion that, during adolescence, individuals may shift some or all attachment functions from their parents to their peers. Hazan and Zeifman (1994) were the first to explore this proposition and they reported that between the ages of 8 and 14 years, adolescents approached peers for proximity and safe haven functions and parents for secure base functions. They also noted that during late adolescence (15-17 years) and adulthood, individuals who had formed peer romantic relationships were less likely to approach their parents for attachment functions. Several researchers have replicated these findings in several different samples but allowed participants to rank several participants, rather than choose one as required by Hazan and Zeifman (see Doherty \& Feeney, 2004; Keren \& Mayseless, 2013; Mayseless, 2004; Nickerson \& Nagle, 2005; Trinke \& Bartholomew, 1997). Interestingly, when participants are asked to rank a list of network members, the researchers have not replicated Hazan and Zeifman's (1994) finding of a preference of peers over parents in young adulthood. As first suggested by Bowlby, the bond with parents, in particular one's mother, seems to continue, at least through to young adulthood (see Pitman \& Scharfe, 2010; Rosenthal \& Kobak, 2010; Scharfe, Pitman, \& Cole, 2017). Despite recent results contradicting Hazan and Zeifman's (1994) initial findings, whether or not parents are replaced by romantic partners in one's social network continues to be disputed.

Since Hazan and Zeifman's original examination of attachment networks, several researchers have explored the structure and function of attachment networks using different methodologies. For example, research has demonstrated that attachment security is associated with placing others closer to the self on a hierarchical mapping technique (the "bull's eye") whereas attachment insecurity is associated with placing others farther away (e.g., Pitman \& Scharfe, 2010; Rowe \& Carnelley, 2005). Research using the bull's eye has been limited in the examination of the placement of others with respect to the "center" (you) and in one study (Rowe \& Carnelley, 2005), the distance between parents. Although the distance between network members could be measured on a paper and pencil version of the bull's eye, with the exception of the distance between parents in Rowe and Carnelley's (2005) study, researchers have not measured distance between network members. This omission is likely due to the time consuming nature of measuring these distances by hand. In this study, an electronic bull's eye was used to more fully explore how attachment may influence the organization of members in our social networks. Specifically, using the electronic bull's eye methodology, it was possible to easily assess the distance between several members of one's network thereby allowing one to test the effects of adult attachment on the organization of social networks.

Several hypotheses were tested. First, consistent with previous research, it was expected that the ranking on the ANQ would be associated with where that individual was placed on the bull's eye. Specifically individuals who were ranked higher on the ANQ would be placed closer to the center "you" on the bull's eye. Second, given the inconsistent findings in the literature, the inclusion of parents versus peers in the hierarchy was 
closely examined. Consistent with Bowlby's proposition, and the findings reported in a few studies (see Pitman \& Scharfe, 2010; Rosenthal \& Kobak, 2010; Scharfe, Pitman, \& Cole, 2017), it was expected that parents, in particular one's mother, would be ranked high on the ANQ and placed closest to the center "you" on the bull's eye regardless of relationship status. Third, as recently suggested by Scharfe, Pitman, and Cole (2017), it was expected that participants who reported higher levels of security with a particular network member (i.e., mother, father, friend and romantic partner) would be more likely to place the corresponding person on their network (e.g., higher security with romantic partners would be associated with partner's inclusion in network). Hypothesis four and five tested the effect of attachment approach and avoidance motivations. Adult attachment was assessed using Bartholomew's 4-category model (see Bartholomew \& Horowitz, 1991; Griffin \& Bartholomew, 1994); each category defined by the underlying dimensions of the self (attachment anxiety) and the other (attachment avoidance). For this study, one's view of others (approach versus avoidance motivations) was expected to be associated with network organization. The fourth hypothesis was that higher security and preoccupied scores, (i.e., attachment approach motivations) were expected to be associated with placing others closer to the center "you" on the bull's eye while higher dismissing and fearful scores (i.e., attachment avoidance motivations) were expected to be associated with placing others farther from the center "you". Finally, Rowe and Carnelley (2005) reported a greater distance between divorced parents compared to married parents on the bull's eye. In this study, the examination of the distance between others on the network was expanded to include both parents and peers. It was expected that secure and preoccupied scores would be positively associated with placing others closer together whereas dismissing and fearful scores would be associated with placing others farther apart. For all hypotheses, Bayesian analyses were utilized to allowed interpretation of the data controlling for the multiple comparisons (and corresponding increased type one error rates) common in this area of research.

\section{Method}

\section{Participants and Procedure}

Participants were undergraduate students from a small, liberal arts university who completed an online survey. Each participant was given a $1 \%$ bonus credit in their psychology class for completing the study. In total 232 of 432 participants completed each of the three tasks (attachment surveys, ANQ, and bull's eye mapping exercise) - Participants completed the attachment surveys first and it was necessary to move to a different site to complete the ANQ and bull's eyes (46\% chose not to continue to the second part of the study). With one exception, there were no differences between participants who only completed the attachment questionnaires and participants who completed each of the three surveys; Participants with just attachment data $(n=198)$ reported lower fearful scores with their mothers than participants with complete data, $t(425)=2.56, p=.01$. As is typical in a university sample, the majority of the participants were female $(77 \%)$, in their first year $(72 \%)$ of university (19\% were in their second year, and $9 \%$ were upper year students) and Caucasian (85\%). Their age ranged from 17 to 49 years $(M=20.53, S D=4.61) ; 88 \%$ were between 18 and 24 years old.

Most participants were dating but not living with their partner $(37 \%)$ or single and not dating $(37 \%)$ while $14 \%$ were single and dating casually and $10 \%$ were living with their partner. Half of the participants $(49.6 \%$, $n=115)$ were in a romantic relationship and relationship length ranged from one month to 23 years $(M=$ 31.71 months, $S D=43.04)$. In terms of family structure, the majority of participants' parents were still married 
(64\%) while $23 \%$ were divorced or separated. At the time of sampling, participants indicated that they currently lived on campus (33\%), off campus with roommates $(25 \%)$, or with their parents/guardian (25\%). Almost all participants reported having a biological sibling $(91 \%)$ while $13 \%$ of participants reported that they had at least one step-sibling and $2 \%$ reported that they had at least one adopted sibling.

\section{Measures}

\section{Relationship Scales Questionnaire}

The Relationship Scales Questionnaire (RSQ; Bartholomew \& Horowitz, 1991; Griffin \& Bartholomew, 1994) is a 17-item continuous measure of attachment composed of short statements regarding the individual's feelings and behaviour towards family members (mother and father), peers (close friends), and romantic partners. Participants rated how well each item described them on a 7-point Likert scale ranging from 1 (not at all like $m e$ ) to 7 (very much like me) and scores were computed for each of the four attachment orientations: secure, fearful, preoccupied, and dismissing. Means, standard deviations, and alphas are reported in Table 1.

Table 1

Means, Standard Deviations, Medians, and Alphas for Attachment Scales for Mother, Father, Peer, and Romantic Partner

\begin{tabular}{|c|c|c|c|c|}
\hline Scale & $M$ & $S D$ & Mdn & $\alpha$ \\
\hline \multicolumn{5}{|c|}{ Mother attachment $(n=225)$} \\
\hline Secure & 4.90 & 1.19 & 5.00 & .66 \\
\hline Fearful & 2.34 & 1.45 & 1.75 & .84 \\
\hline Preoccupied & 3.21 & 0.94 & 3.25 & .18 \\
\hline Dismissing & 3.82 & 1.31 & 3.80 & .76 \\
\hline \multicolumn{5}{|c|}{ Father attachment $(n=215)$} \\
\hline Secure & 4.57 & 1.23 & 4.60 & .60 \\
\hline Fearful & 2.70 & 1.74 & 2.25 & .88 \\
\hline Preoccupied & 3.17 & 1.01 & 3.25 & .18 \\
\hline Dismissing & 3.99 & 1.42 & 4.00 & .80 \\
\hline \multicolumn{5}{|c|}{ Peer attachment $(n=215)$} \\
\hline Secure & 5.18 & 0.95 & 5.20 & .46 \\
\hline Fearful & 2.70 & 1.30 & 2.50 & .80 \\
\hline Preoccupied & 3.83 & 0.95 & 3.75 & .16 \\
\hline Dismissing & 3.61 & 1.12 & 3.60 & .71 \\
\hline \multicolumn{5}{|c|}{ Partner attachment $(n=148)$} \\
\hline Secure & 5.31 & 1.11 & 5.40 & .64 \\
\hline Fearful & 2.58 & 1.35 & 2.50 & .78 \\
\hline Preoccupied & 4.22 & 0.98 & 4.00 & .25 \\
\hline Dismissing & 3.54 & 1.21 & 3.60 & .73 \\
\hline
\end{tabular}

\section{Attachment Networks Questionnaire}

Attachment Networks Questionnaire (ANQ; Trinke \& Bartholomew, 1997). Participants were asked to list individuals whom the participants "felt a strong emotional tie, whether positive or negative" up to a maximum of 15. Participants were then asked to rank each person on 7 questions pertaining to several attachment functions: safe haven, secure base, proximity seeking, conflictual emotions and degree of emotional connection (see Trinke \& Bartholomew, 1997). An average of the seven questions was calculated for each person on the list and this average was used as an estimate of the ranking for that person. The difference in ranking between 
members of one's network reflects the difference in strength of the attachment bonds where higher rankings reflect stronger attachment bonds. Standardized alphas of the seven items ranged from .84 for romantic partners to .92 for siblings.

Participants listed between $1-15$ individuals on the ANQ $(M=11.84, S D=3.99)$. Nearly all participants listed their mother $(94 \%)$, while $82 \%$ listed father, $91 \%$ listed one or more friends, $83 \%$ listed one or more siblings, and $43 \%$ listed a romantic partner. See Table 2 for means, medians, standard deviations, and ranges for the ANQ data.

Table 2

Means, Medians, Standard Deviations, and Ranges of ANQ and Bull's Eye Data

\begin{tabular}{|c|c|c|c|c|c|}
\hline Scale & $M$ & Mdn & $S D$ & Range & $n$ \\
\hline \multicolumn{6}{|l|}{ ANQ } \\
\hline Mother ranking & 2.38 & 2.00 & 1.55 & $1.00-12.57$ & 217 \\
\hline Father ranking & 3.45 & 3.00 & 1.87 & $1.00-11.00$ & 181 \\
\hline Sibling ranking & 4.43 & 4.00 & 2.16 & $1.00-12.86$ & 179 \\
\hline Peer ranking & 3.94 & 3.71 & 1.86 & $1.00-10.00$ & 211 \\
\hline Partner ranking & 2.52 & 2.00 & 2.14 & $1.00-13.00$ & 100 \\
\hline \multicolumn{6}{|c|}{ Bull's eye distance from "you" to } \\
\hline Mother & 53.82 & 45.00 & 63.83 & $1.00-459.14$ & 217 \\
\hline Father & 59.15 & 47.42 & 50.99 & $1.12-359.59$ & 190 \\
\hline Sibling & 56.05 & 47.29 & 42.21 & $2.06-312.58$ & 193 \\
\hline Peer & 64.58 & 49.87 & 43.40 & $1.80-270.01$ & 216 \\
\hline Partner & 47.54 & 40.51 & 43.69 & $1.12-235.90$ & 101 \\
\hline \multicolumn{6}{|c|}{ Bull's eye distance between } \\
\hline Mother and father & 64.64 & 47.63 & 53.12 & $1.00-457.67$ & 184 \\
\hline Mother and sibling & 73.29 & 68.31 & 50.50 & $1.41-497.56$ & 187 \\
\hline Mother and peer & 83.99 & 78.25 & 47.75 & $1.00-374.55$ & 204 \\
\hline Mother and partner & 70.92 & 51.27 & 55.99 & $5.10-425.69$ & 96 \\
\hline Father and sibling & 73.79 & 65.00 & 45.56 & $1.00-290.30$ & 165 \\
\hline Father and peer & 91.46 & 82.76 & 48.35 & $2.24-267.30$ & 181 \\
\hline Father and partner & 79.59 & 71.90 & 49.12 & $23.60-267.30$ & 86 \\
\hline Peer and sibling & 89.67 & 81.62 & 41.17 & $2.24-245.46$ & 184 \\
\hline Peer and partner & 83.19 & 77.23 & 41.61 & $22.20-202.20$ & 92 \\
\hline Partner and sibling & 76.66 & 63.33 & 44.78 & $16.12-254.48$ & 88 \\
\hline
\end{tabular}

Note. As not all participants listed each of the five types of relationships, the $n$ 's for each comparison are included. The maximum distance from "you" is 460 but the distance between network members was calculated using the hypotenuse of the triangle and could range as long as 920 if the individuals were placed on opposite sides of the same axis.

Participants were categorized into one of 4 groups using the number of people they listed on the ANQ, $49 \%$ ( $n$ $=114$ ) listed 15 people, $23 \%$ listed 10-14 $(n=53), 19 \%$ listed 6-9 $(n=44)$, and $9 \%$ listed $1-5$ people $(n=21)$, and these groups were used to determine if there were attachment differences among participants who listed a different number of people on the ANQ. With one exception, there were no attachment differences between the 4 network groups; there was an overall significant $F$ with peer preoccupied scores, $F(3,223)=3.12, p=.03$ and a Tukey test revealed that participants who listed 10-14 members on the ANQ reported higher preoccupied scores than participants who listed 6-9 members. Furthermore, there were no differences between the groups on where (i.e., how close) participants placed their mother, father, closest sibling, closest friend, and romantic 
partner on the electronic bull's eye. There were also no significant correlations between the total number of people listed on the ANQ and the attachment scales for mother, father, friend or romantic partner ( $r$ 's ranged from -.11 to .11).

\section{Hierarchical (Bull's Eye) Mapping Technique}

Hierarchical (Bull's Eye) Mapping Technique (Antonucci, 1986). Using the bull's eye method, participants were asked to place individuals who they listed on the ANQ onto an electronic diagram of a target (coded using Java). Participants were instructed that individuals placed on the innermost circle are those people who the participant cannot imagine living without and to place others in the middle or furthest circle depending on how important they are to the participant (see Antonucci, 1986). A marker representing 'You' (the participant) was placed at the center (the bull's eye) of the concentric circles comprising the target, and the participant was asked to move a marker representing each individual listed on the ANQ onto the target at a distance that the participant believed represented their closeness to the individual. The diagram was "static", distance measured as part of the Java code, and the data saved for each individual placed on the bull's eye represented the $X$ (ranging from 0 to 460 ) and $Y$ (ranging from 0 to 460) coordinates from the center "you" $(0,0)$; data included both the $x$ and $y$ coordinates. Numbers closer to zero indicate that the bull's eye marker for that member of the network was placed closer to the center of that axis; higher numbers (up to 460) indicated that the marker for that member of the network was placed farther away.

Where participants could list more than one person (e.g., siblings, friends), the current analyses focused on the closest person in that category. For example, to determine the closest sibling for individuals with more than one sibling, the sibling who was placed closest to the centre of the bull's eye ("you") was considered the closest sibling and was used for the remaining sibling analyses (103 female and 90 male siblings). Some individuals listed up to four friends, so the same procedure was employed to determine the closest peer. Data for girlfriends, boyfriends, husbands, and wives was aggregated to create a romantic partner category. For all relationships (mother, father, closest sibling, closest peer, and romantic partner), the distance from "you" on the bull's eye ranged from very close (1.0 to 2.1) to very far (235.90 to 459.14). See Table 2 for means, standard deviations, and ranges for the bull's eye data. Not surprisingly, the total number of people listed on the ANQ (and therefore plotted on the bull's eye) was associated with the total area of the social network on the bull's eye, $r(232)=.37, p<.001$, as well as the farthest distance on the bull's eye, $r(232)=.17, p=.012$.

\section{Results}

To test the hypothesis that the ranking on the ANQ would be associated with where that individual was placed on the bull's eye, the average of the ANQ scales and the distance from the center "you" on the bull's eye were compared. As expected, there was a positive association between ranking and distance; In other words, network members who were ranked higher on the ANQ were placed closer to "you" on the bull's eye: mother, $r(217)=.20, p=.003$; father, $r(181)=.31, p<.001$; closest sibling $r(179)=.33, p<.001$; closest friend $r(211)$ $=.25, p<.001$; romantic partner, $r(100)=.52, p<.001$. Although these findings are consistent with what would be expected from Bowlby's theory as well as previous empirical work, the fact remains that, due to the multiple comparisons, the findings may be due to type one error. One way to address high type one error rates is to utilize Bayesian analyses and compare with the traditional frequentist or inferential approaches (Pernet, 2017). Associations with a Bayes factor from 3-10 indicates moderate support for the alternative hypothesis, 10-30 
indicates strong support and greater than 30 indicates very strong support. In this case, for the correlations presented above, the Bayes factors calculated using JASP Version 0.12 (jasp-stats.org) ranged from 5.99 for mothers to 436986.53 for romantic partners suggesting that the findings were in favor of the alternative hypothesis. For example, a Bayes factor of 5.99 suggests that the alternative hypothesis (i.e., that there would be a positive association between the ANQ ranking of mother and distance from the center "you" that mother was placed on the bull's eye) predicts these data 5.99 times better than the null hypothesis.

Next, the inclusion of parents versus peers in the hierarchy was examined. Consistent with some previous work (Pitman \& Scharfe, 2010; Rosenthal \& Kobak, 2010; Scharfe et al., 2017), the majority of participants (50\%) rated their mother \#1 on the ANQ, followed by their romantic partner $(21 \%)$, their closest friend $(15 \%)$, their father $(9 \%)$, and their closest sibling (5\%). These frequencies were recalculated for participants who reported that they were currently in a romantic relationship $(n=115)$ and the results were quite similar to above: the majority $(60 \%)$ did not list their romantic partner as \#1. Specifically, 40\% rated their romantic partner \#1 on the ANQ, followed by mother $(36 \%)$, closest friend $(14 \%)$, father $(6 \%)$, and closest sibling $(4 \%)$. The chi-square difference test did suggest that there were differences between the two relationship groups (in relationships and not in relationships) $X^{2}(d f=4)=20.57, p<.001$. It is important to note, however, that romantic partners were not automatically listed \#1 on the ANQ - in fact, only 101 of the 115 participants (88\%) who were in a current romantic relationship listed their romantic partner on the ANQ and only $46(40 \%)$ ranked their romantic partner at the top of their list.

Similar results were found with the bullseye: $34 \%$ placed their mother closest to "you" while $21 \%$ placed romantic partner closest, 19\% sibling, 19\% father, and $7 \%$ closest friend. Once again, these frequencies were recalculated for participants who reported that they were currently in a romantic relationship $(n=115)$ and the results were quite similar: $33 \%$ placed their mother closest to the "you" center, $17 \%$ romantic partner, $20 \%$ sibling, $20 \%$ father, and $10 \%$ closest friend.

As recently suggested by Scharfe, Pitman, and Cole (2017), it was expected that participants who reported higher levels of security with a particular network member (i.e., mother, father, romantic partner) would be more likely to place the corresponding person on their network (e.g., higher security with mothers would be associated with mothers inclusion in network). To test this hypothesis, the attachment scores for individuals who listed their mother, father, or romantic partner and individuals who did not list their mother, father, or romantic partner were compared. Once again, Bayesian analyses were computed as multiple comparisons increased the likelihood of type one errors. Consistent with expectations, individuals who listed their mother in their network $(n=216)$ were significantly more likely to report higher mother secure scores (4.95 versus 4.06, Bayes factor $=5.50$ suggesting moderate support for the alternative hypothesis) than individuals who did not list their mother $(n=13)$. Furthermore, individuals who listed their father in their network $(n=189)$ were significantly more likely to report higher father secure scores (4.63 versus 4.02 , Bayes factor $=4.06$ suggesting moderate support for the alternative hypothesis), lower father fearful scores (2.55 versus 3.69, Bayes factor $=47.28$ suggesting very strong support for the alternative hypothesis) and lower father dismissing scores (3.87 versus 4.78 , Bayes factor $=34.13$ suggesting very strong support for the alternative hypothesis) than individuals who did not list their father $(n=32)$. Interestingly, there was no support that attachment was associated with whether participants listed their romantic partner. For these analyses, the Bayes factors indicated that any differences between individuals who listed their romantic partner in their network $(n=95)$ and individuals who did not list their partner $(n=19)$ could be treated as anecdotal. 
Next, the hypothesis that approach-avoidance attachment motivations would be associated with bull's eye placement was tested for each of the attachment scales and the distance from "you" to corresponding network members. See Table 3. For example, the association between mother attachment scales and the distance from "you" (center of the bull's eye) to where the participant placed their mother was calculated. Overall the pattern of results suggests that higher attachment security scores were associated with placing network members closer to "you" whereas higher avoidance scores - both fearful and dismissing - were associated with placing network members farther away from "you" for attachment to mother, father, peer, and partner.

Table 3

Correlations Among Attachment to Mother, Father, Peer, and Romantic Partner With Distance From Centre "You" and Between Network Members

\begin{tabular}{|c|c|c|c|c|c|}
\hline Scale & $n$ & Secure & Fearful & Preoccupied & Dismissing \\
\hline \multicolumn{6}{|c|}{ Mother attachment - Distance from mother } \\
\hline to "you" & 216 & -.15 & $.21^{\mathrm{b}}$ & -.06 & $.21^{\mathrm{a}}$ \\
\hline to dad & 183 & $-.21^{\mathrm{a}}$ & $.22^{\mathrm{a}}$ & -.11 & $.22^{\mathrm{a}}$ \\
\hline to sibling & 187 & $-.33^{c}$ & $.32^{\mathrm{c}}$ & -.07 & $.27^{\mathrm{c}}$ \\
\hline to friend & 204 & -.02 & .07 & -.02 & .03 \\
\hline to partner & 95 & -.22 & $.29^{\mathrm{a}}$ & -.08 & $.34^{\mathrm{c}}$ \\
\hline \multicolumn{6}{|c|}{ Father attachment - Distance from father } \\
\hline to "you" & 190 & $-.25^{\mathrm{c}}$ & $.40^{\mathrm{c}}$ & -.04 & $.29^{\mathrm{C}}$ \\
\hline to mom & 184 & $-.29^{c}$ & $.31^{\mathrm{c}}$ & .02 & $.34^{\mathrm{c}}$ \\
\hline to sibling & 165 & $-.25^{\mathrm{b}}$ & $.34^{\mathrm{c}}$ & .06 & $.26^{\mathrm{b}}$ \\
\hline to friend & 181 & -.15 & $.24^{\mathrm{b}}$ & .00 & .13 \\
\hline to partner & 86 & -.23 & $.27^{\mathrm{a}}$ & -.01 & .26 \\
\hline \multicolumn{6}{|c|}{ Peer attachment - Distance from peer } \\
\hline to "you" & 216 & -.17 & $.19^{\mathrm{a}}$ & -.04 & .15 \\
\hline to mom & 204 & -.06 & .13 & .01 & .17 \\
\hline to dad & 181 & -.15 & $.20^{\mathrm{a}}$ & .01 & .09 \\
\hline to sibling & 184 & -.13 & $.20^{\mathrm{a}}$ & .13 & .09 \\
\hline to partner & 92 & -.09 & .14 & -.08 & .05 \\
\hline \multicolumn{6}{|c|}{ Partner attachment - Distance from partner } \\
\hline to "you" & 95 & $-.27^{\mathrm{a}}$ & $.44^{\mathrm{c}}$ & -.01 & $.36^{\mathrm{c}}$ \\
\hline to mom & 91 & $-.29^{\mathrm{a}}$ & .22 & -.06 & $.35^{\mathrm{c}}$ \\
\hline to dad & 81 & -.14 & $.28^{\mathrm{a}}$ & .13 & .16 \\
\hline to friend & 88 & -.00 & .02 & -.01 & -.02 \\
\hline to sibling & 81 & $-.28^{\mathrm{a}}$ & $.28^{\mathrm{a}}$ & .15 & .20 \\
\hline
\end{tabular}

Note. Guide for $p$ values is listed in the text. As not all participants listed each of the five types of relationships, the $n$ 's for each comparison are included. Additional information about the Bayesian values are provided in the text.

${ }^{\mathrm{a} B F} 10>3 .{ }^{\mathrm{b}} \mathrm{BF} 10>10 .{ }^{\mathrm{B}} \mathrm{BF} 10>30$.

The findings above replicated what would be expected based on previous research using a paper and pencil version of the bull's eye - security is associated with placing others closer to oneself whereas avoidance is associated with placing others farther away. This finding has been reported previously (e.g., Julal et al., 2107; Rowe \& Carnelley, 2005). To date, however, researchers have not thoroughly examined the distance between network members on the bull's eye (cf. Rowe \& Carnelley, 2005). As discussed above, one of the distinct advantages with an electronic version of the bull's eye is that the data include coordinates for each of the network members in the bull's eye space and using these coordinates it was possible to easily measure not only the 
distance between "you" and the network member but the distance between each of network member (Distance

$\left.=\sqrt{ } \mid\left[\text { person } A_{x \text { axis }}+\text { person } B_{x \text { axis }}\right]^{2}+\left[\text { person } A_{y} \text { axis }+ \text { person } B_{y \text { axis }}\right]^{2}\right)$. These data assist in understanding the organization of attachment networks - not only how close others are perceived to "you" but how close they are perceived to be to each other. Although Rowe and Carnelley (2005) presented data to support that divorced parents were placed farther apart from married parents, they did not examine the distance between other network members or the effect of attachment on the distance. The data in this study replicated Rowe and Carnelley's finding that parents who were not married were place farther apart from each other $(n=47, M=$ $84.75)$ than parents who were married $(n=135, M=58.08$, Bayes factor $=11.083$ suggesting strong support for the alternative hypothesis). These analyses were expanded to test the association between attachment on the distance between each of the 5 relationships (not just mother and father) and it was expected that secure and preoccupied scores would be positively associated with placing others closer together whereas dismissing and fearful scores would be associated with placing others farther apart.

Using the distance data, the associations between attachment scales and the distance between network members were calculated. Not surprisingly, for the majority of the correlations, security was associated with placing others closer together and both fearful and dismissing scores (both measuring a type of insecure-avoidance) were associated with placing others farther apart. Although this pattern of results is quite consistent with what would be expected from Bowlby's theory as well as previous empirical work, the fact remains that the type one error rate for the multiple correlations is quite high and Bayesian analyses were also utilized to compare to the $p$ values. For example, in Table 3, the effect size of the correlations ranged from small $(r=.10)$ to moderate $(r=.30)$ and, given the sample sizes, correlations around .15 were significant at $p=.05$. Associations with a Bayes factors greater than three (i.e., at least moderate support for the alternative hypothesis) are highlighted in Table 3: Overall, the pattern of significant Bayes factors in Table 3 supports the interpretation that security was associated with placing others closer together and both fearful and dismissing scores were associated with placing others farther apart.

Interestingly, preoccupied scores were not associated with the ranking or distance data and posthoc analyses were run to explore these null findings. As these are posthoc analyses, they should be interpreted with caution and need to be replicated. Following a suggestion made by Scharfe (2016) the four items in the preoccupied scale were further divided into the 2 preoccupied anxiety items and the 2 preoccupied approach items. Interestingly, and consistent with Scharfe (2016), this division increased the reliability of the subscales (standardized alphas increased from .18 to .41 for mother preoccupied anxiety and .40 for father preoccupied anxiety and .77 for mother preoccupied approach and .75 for father preoccupied approach) and further explained the null findings. Preoccupied anxiety scores were negatively associated with ranking of mothers, $r(218)=-.28$, Bayes factor $=582.198$, and fathers, $r(181)=-.27$, Bayes factor $=68.116$, as well as the distance from the centre to fathers, $r(190)=-.21$, Bayes factor $=5.177$ and peers, $r(216)=-.19$, Bayes factor $=3.616$. In contrast, preoccupied approach scores were positively associated with ranking of mothers, $r(218)=.21$, Bayes factor $=$ 8.47, and fathers, $r(180)=.31$, Bayes factor $=1025.702$.

\section{Discussion}

In this study, the associations between attachment representations and where participants placed members of their social network on an electronic bull's eye were explored. Many of the findings replicated previous 
research, however, due to the multiple comparisons - which increases type one error rates - the $p$ values were compared to Bayesian analysis to further test the significance of the statistical differences. First, despite the null associations between attachment scales and number of people listed in participants' networks, attachment security was associated with placing fathers and partners closer to the center "you" on the bull's eye and attachment avoidance - both fearful and dismissing attachment - was associated with placing mothers, fathers, and partners farther away. Rowe and Carnelley's (2005) finding that divorced parents were placed farther apart on the bull's eye was also replicated, however, this study extended their previous research by examining the distance between all combinations of the five network members and the findings suggested that our attachment representations may be associated with our perceptions of how close others are to each other. As expected, in several but not all comparisons, attachment security was associated with the tendency to place network members closer to each other while both attachment avoidance scores (fearful and dismissing) were associated with placing network members farther from each other. These findings suggest that attachment representations may influence the organization of one's social network - both how close we perceive we are to others as well as how close we perceive they are to each other. Interestingly, however, participants were not instructed to consider the distances between others - just the distance from the center "you" - and it may be that the findings do not represent an organization of one's social network but some other variable (e.g., whether others in their life know each other).

It should not be surprising that security was associated with placing network members closer to each other on the bull's eye than fearful-avoidant and dismissing-avoidant ratings. This finding suggests that individuals with high attachment avoidance scores seemed to be motivated to keep their network members at a distance; however, it may also be that individuals whose network members are not "close" would also report higher attachment avoidance. This may be the first study to report these findings using the 4-category model but they are consistent with what would be expected. Secure individuals have been found to be more open and trusting in relationships (e.g., Bartholomew \& Horowitz, 1991; Griffin \& Bartholomew, 1994; Han, 2017) and would be expected to have more cohesive social networks (cf., Kaźmierczak \& Błażek, 2015). Avoidant individuals, on the other hand, would be expected to keep others in their network at a distance from themselves (cf., Arriaga \& Kumashiro, 2019; Bartholomew \& Horowitz, 1991; Griffin \& Bartholomew, 1994) as well as apart from each other as a way to maintain emotional and physical distance in their relationships.

The findings also add to the list of studies that suggest that, at least for emerging adults, romantic partners do not necessarily jump to the top of the hierarchy supporting the recent work suggesting that healthy young adults continue to place parents in their network (e.g., Pitman \& Scharfe, 2010; Rosenthal \& Kobak, 2010; Scharfe et al., 2017). In particular, mothers continued to play an important role in attachment networks and were not jettisoned from the network at the mere appearance of a romantic partner. In fact, only $40 \%$ of participants who were in relationships rated their partner as their \#1 attachment figure and only $17 \%$ placed their partner closest to the center "you" on the bull's eye. Although there does continue to be controversy surrounding Hazan and Zeifman's (1994) original finding that adults in romantic relationships place their partner first, these data, and results from several other studies, suggest that it is not the case for all and further research needs to explore these inconsistent findings. Furthermore, the findings suggested that quality of attachment with mothers and fathers was not associated with whether parents are listed the network or not. These findings are in contrast to the suggestion that individuals may be replacing insecure family relationships with secure peer relationships (see Keren \& Mayseless, 2013; Pitman \& Scharfe, 2010). Furthermore, there was no support for the proposal that individuals who list their romantic partner in their network have a more secure relationship with that partner 
than individuals in relationships who did not list their partner. It may be productive, in future studies, to explore how variables such as quality of, or satisfaction in, relationships may help to explain the process of adding new partners (or friends) to our attachment networks (cf. Keren \& Mayseless, 2013).

Despite the fact that these data replicated previous findings, there are a few limitations that should be addressed in future work. First, the sample consisted of young adults attending a post-secondary institution and a sample of older participants may be more likely report somewhat different networks and may be more likely to report primary importance of their peer networks. Second, participants' current stress was not assessed in this study and it may be that participants experiencing heightened stress were more likely to report primary attachment figures (i.e., their mother). Furthermore, work is needed to determine if (and how) networks change during stressful transitions to determine if perceived stress helps to explain the inconsistent mother/partner findings. These data were taken at one time and place and, although associations were strong, it is not possible to determine if individuals with, for example, closer networks felt more secure or if individuals who felt more secure reported closer social networks. Finally, although an improved RSQ to assess the 4-category model of attachment has recently been published (see Scharfe, 2016), these data were collected before that survey was developed and the attachment data - in particular, the preoccupied scale - are limited by lower reliability. Post-hoc analyses did suggest that the preoccupied ratings were capturing the essence of the scale, however, these are posthoc analyses should be interpreted with caution, and future research using T-RSQ (Scharfe, 2016) would be needed to test out this hypothesis.

In conclusion, the results of this study further support Bowlby's proposal that individuals organize their attachment figures into a hierarchy. The findings also supported previous work suggesting that parents, in particular mothers, continue to be important in the lives of emerging adults, even emerging adults who are in romantic relationships. The results also provided some insights into the importance of attachment representations for the organization of social networks. In particular, attachment security was associated with placing others closer together and attachment avoidance (both fearful and dismissing) was associated with placing others farther apart. These findings are consistent with our current understanding of individual differences of attachment: individuals with high attachment security may be more likely to integrate the members of their social networks whereas individuals with high attachment avoidance would be expected to keep their network members at a distance. Finally, using Bayesian analyses it was possible to control for the high type one error rate, resulting from the multiple comparisons, and provide a more conservative test of the significance of the findings.

\section{Funding}

The author has no funding to report.

\section{Competing Interests}

The author has declared that no competing interests exist.

\section{Acknowledgments}

I am grateful to Peter Northup for programming the electronic bull's eye and contributions of Gillian Tibbetts and Robyn Pitman to this project. 


\section{Author Note}

Portions of these data were presented at the International Association of Relationship Research Conference, Chicago, IL, USA, July 2012 (Tibbetts, Scharfe, \& Pitman, 2012).

\section{References}

Antonucci, T. C. (1986). Hierarchical mapping technique. Generations: Journal of the American Society on Aging, 10, 10-12.

Arriaga, X. B., \& Kumashiro, M. (2019). Walking a security tightrope: Relationship-induced changes in attachment security. Current Opinion in Psychology, 25, 121-126. https://doi.org/10.1016/j.copsyc.2018.04.016

Bartholomew, K., \& Horowitz, L. (1991). Attachment styles among young adults: A test of a four-category model. Journal of Personality and Social Psychology, 61, 226-244. https://doi.org/10.1037/0022-3514.61.2.226

Bowlby, J. (1969/1997). Attachment and loss: Vol. 1. attachment. London, United Kingdom: Pimlico.

Doherty, N. A., \& Feeney, J. A. (2004). The composition of attachment networks throughout the adult years. Personal Relationships, 11, 469-488. https://doi.org/10.1111/j.1475-6811.2004.00093.x

Kaźmierczak, M., \& Błażek, M. (2015). Attachment styles as predictors of the perception of couples' cohesion. Social Behavior and Personality, 43, 1055-1056. https://doi.org/10.2224/sbp.2015.43.6.1055

Keren, E., \& Mayseless, O. (2013). The freedom to choose secure attachment relationships in adulthood. The Journal of Genetic Psychology, 174, 271-290. https://doi.org/10.1080/00221325.2012.681326

Griffin, D. W., \& Bartholomew, K. (1994). The metaphysics of measurement: The case of adult attachment. In K. Bartholomew \& D. Perlman (Eds.), Advances in personal relationships: Vol 5. attachment processes in adulthood (pp. 17-52). London, United Kingdom: Jessica Kingsley.

Han, S. (2017). Attachment insecurity and openness to diversity: The roles of self-esteem and trust. Personality and Individual Differences, 111, 291-296. https://doi.org/10.1016/j.paid.2017.02.033

Hazan, C., \& Zeifman, D. (1994). Sex and the psychological tether. In K. Bartholomew \& D. Perlman (Eds.), Advances in personal relationships: Vol 5. attachment processes in adulthood (pp. 151-178). London, United Kingdom: Jessica Kingsley.

Julal, F. S., Carnelley, K. B., \& Rowe, A. (2017). The relationship between attachment style and placement of parents in adults' attachment networks over time. Attachment \& Human Development, 19, 382-406. https://doi.org/10.1080/14616734.2017.1316751

Mayseless, O. (2004). Home leaving to military service: Attachment concerns, transfer of attachment functions from parents to peers, and adjustment. Journal of Adolescent Research, 19, 533-558. https://doi.org/10.1177/0743558403260000

Nickerson, A. B., \& Nagle, R. J. (2005). Parent and peer attachment in late childhood and early adolescence. The Journal of Early Adolescence, 25, 223-249. https://doi.org/10.1177/0272431604274174 
Pernet, C. (2017). Null hypothesis significance testing: a guide to commonly misunderstood concepts and recommendations for good practice [Version 5; peer review: 2 approved, 2 not approved]. F1000 Research, 4, Article 621. https://doi.org/10.12688/f1000research.6963.4

Pitman, R., \& Scharfe, E. (2010). Testing the function of attachment hierarchies during emerging adulthood. Personal Relationships, 17, 201-216. https://doi.org/10.1111/j.1475-6811.2010.01272.x

Rosenthal, N. L., \& Kobak, R. (2010). Assessing adolescents' attachment hierarchies: Differences across developmental periods and associations with individual adaptation. Journal of Research on Adolescence, 20, 678-706. https://doi.org/10.1111/j.1532-7795.2010.00655.x

Rowe, A. C., \& Carnelley, K. B. (2005). Preliminary support for the use of a hierarchical mapping technique to examine attachment networks. Personal Relationships, 12(4), 499-519. https://doi.org/10.1111/j.1475-6811.2005.00128.x

Scharfe, E. (2016). Measuring what counts: Development of a new 4-category measure of adult attachment. Personal Relationships, 23, 4-22. https://doi.org/10.1111/pere.12105

Scharfe, E., Pitman, R., \& Cole, V. (2017). Changing attachment hierarchies: An exploration of the function of the shift from parents to peers. Interpersona, 11, 40-54. https://doi.org/10.5964/ijpr.v11i1.223

Tibbetts, G., Scharfe, E., \& Pitman, R. (2012, July). Siblings in social networks: A Bull's Eye perspective [Poster presentation]. International Association of Relationship Research Conference, Chicago, IL, USA.

Trinke, S. J., \& Bartholomew, K. (1997). Hierarchies of attachment relationships in young adulthood. Journal of Social and Personal Relationships, 14, 603-625. https://doi.org/10.1177/0265407597145002 